\title{
Impact of Educational Intervention on Secondary School Students' Knowledge, Practices and Attitudes Regarding to COVID-19
}

Manal Mohamed Ahmed Ayed1 ( $\square$ manal_ayed@yahoo.com )

Faculty of Nursing, Sohag University, Sohag, Egypt, https://orcid.org/0000-0003-0922-5823

Amel abd Elaziem Mohamed

Faculty of Nursing, Beni- Suef University

Thorea Mohamed Mahmoud

Faculty of Nursing, Sohag University, Sohag, Egypt,

Seham Mohammed AbdElaziz

Faculty of Nursing, Benha University, Egypt

\section{Research Article}

Keywords: COVID -19, educational intervention, knowledge, attitudes, practices, students

Posted Date: September 29th, 2020

DOI: https://doi.org/10.21203/rs.3.rs-60327/v2

License: (c) (i) This work is licensed under a Creative Commons Attribution 4.0 International License. Read Full License 


\section{Abstract}

Background: Coronavirus pandemic disease 2019 is considered an emerging respiratory disease that is highly infectious and is caused by coronavirus and was detected in December 2019 in Wuhan, China. Coronavirus has affected educational systems worldwide and led to the total closures of schools, universities, and colleges, in the middle of March 2020. The study aimed to evaluate the impact of educational intervention on secondary school students' knowledge, practical knowledge and attitudes regarding to COVID-19.

Methods: A pre/post quasi-experimental design was adopted. A total of 260 students were selected at secondary school students in Sohag City in the study from 20 April to 2 May 2020. The tools utilized in this study consists of: A self-administered questionnaire which contains four parts to assess secondary school students' demographic, knowledge regarding COVID -19, the attitude toward COVID -19 and practice regarding COVID -19 and health education Arabic booklet was prepared by the researchers. The COVID-19 related questionnaire was designed using Google forms regarding the COVID-19, the link of the survey was sent to the respondents via Facebook and Whatsapp groups.

Results: A statistically significant difference between secondary students' knowledge attitudes, and practices before and after educational intervention. 202 (77.7\%) had a poor pretest attitude level followed by fair (20.0\%) and good 6 (2.3\%). In the posttest, all 260 students had a good attitude level which improved after educational intervention implementation. (57.7\%) had poor pretest practice levels followed by fair (38.3\%) and good $10(4.0 \%)$.

Recommendations: It is important to encourage cooperation between educational institutions, medical care providers, and health personnel to educate secondary school students about COVID-19.

\section{Introduction}

By the end of January 2020, the World Health Organization (WHO) declared a public health emergency of international concern and called for the collaborative efforts of all countries to prevent the rapid spread of COVID-19 (World Health Organization, 2020 and Tang et al., 2020).. The WHO declared COVID-19 as a global pandemic on 12 March, which has spread widely and rapidly, from Wuhan city to other parts of the world, and threatens the lives of many people (World Health Organization, 2020). Extraordinary efforts have been implemented to control the rapid spread of COVID-19 in Egypt. Its clinical presentation ranges from being an asymptomatic infection and developing into severe disease and is associated with a high mortality rate (Carsetti et al., 2005). At the time of writing (May 16, 2020), over 4,425,485 COVID-19 cases and 302, 059 deaths have been registered worldwide (World Health Organization, 2020). In Egypt, there are 11,228 positive individuals and 592 deaths (Ministry of Health-Egypt, 2020). Coronavirus is characterized by rapid transmission that occurs through close contact with an infected person and is not the only method of transmission (WHO Coronaviruses, 2020). Some of the signs and symptoms of 
coronavirus include fever, dry cough, fatigue, myalgia, dyspnea, sore throat, runny nose, and sneezing. Images that illustrate the Morphology of Coronaviruses; the club-shaped viral spike polymers, colored red, create the look of a corona surrounding the vision when observed with an electron (Shereen et al., 2020). The mortality rate soared and the ease of spread was upsetting. Research shows that older people and those with underlying medical problems such as cardiovascular diseases, diabetes, chronic respiratory disease, and cancer are more likely to develop serious illnesses from coronavirus (World Health Organization, 2020). All aspects of human activities globally affected by the outbreak of COVID-19 ranged from education, research, sports, entertainment, transportation, worship, social gathering/interactions, economy, businesses, and politics. Indeed, the entire world was in distress as a result of COVID-19 threats (Taber, 2020). There was closure in most parts of the world, and persons were asked to work from home. Some countries even deployed their military to enforce coronavirus restrictions, and to reduce the number of covidiots. There was an increased need for health equipment including, protective gowns, sanitizers, face masks, and hand gloves (National Health Commission of the People's Republic of China, 2020). Substantial efforts to control the disease have been made by health authorities through various measures. Public education is considered one of the most important measures that can help control diseases. Efforts to control the spread of COVID-19 including non-pharmaceutical interventions and preventive measures such as social-distancing and self-isolation have prompted widespread efforts (Jordan, 2020) There were no reliable treatments for Coronavirus, as at the time of this study, but a series of studies were in the pipeline across the world towards discovering a clinical vaccine for the contagion. However, recent events show that behavioral change can help contain the spread of coronavirus (The Novel Coronavirus Pneumonia Emergency Response Epidemiology Team, 2020). Some of the suggested measures to halt the coronavirus pandemic include improved individual habits such as personal hygiene, including constant washing of hands with alcohol-based sanitizers, good respiratory attitude (close coughing and sneezing), and other personal protection practices such as wearing of face mask, avoiding touching of the face, social distancing, and reducing contacts with people by self-isolation at home or avoiding nonessential travels or gatherings. Coronavirus considered a global problem that requires more action coordination and global cooperation to successfully contain the outbreak and to deal with its aftermath effects. The consequences of COVID-19 could be more severe; if people do not comply or adhere strictly to public health regulations and advice (World Health Organization, 2020). With the absence of any definite therapy against COVID-19, it becomes imperative that people must stringently abide by advisories of social distancing and hand washing ( $\mathrm{Pal}$ and Bhansali, 2020 \& Pal and Bhadada, 2020 and Banerjee et al., 2020). Knowledge, attitude, and practices towards COVID-19 are affected by people's adherence to these control measures, following the "KAP theory". The "KAP theory" is a health behavior change theory wherein the change in human behavior includes three successive items, namely, gaining the right knowledge, generating attitudes and adopting practice (Fan et al., 2020). Many studies have illustrated that the KAP level in individuals is associated with effective prevention and management of illness and promotion of one's health (Fan et al., 2020 \& Matsumoto et al., 2015 \& Rana et al., 2020, Khalil and Abdalrahim, 2014) because deficiencies in KAP are associated with poor health and maladaptive disease preventive behavior, (Matsumoto et al., 2015 and Ricardo et al., 2018). The nurse plays an important role in preventing the spread of the disease by 
encouraging students with adherence which is influenced by the student's knowledge, attitudes, and practice toward COVID-19 and providing health education about COVID-19 prevention and control. Evidence shows that student knowledge is important in managing pandemics (Chirwa, 2020 and Chirwa 2019). Many facts about students' perceptions and practices can be gained by assessing students' knowledge about coronavirus which helps to identify attributes that affect the students' adoption of healthy practices and responsive behavior (Podder et al., 2019). There was a need to understand the student's knowledge, attitudes, and practice toward COVID-19 at this critical moment. As members of the health care team, nurses play an essential role in patient care, which includes contributing to the decision-making process within the multidisciplinary health care team, taking responsibility for nursing care, prevention, health educator, and assessment of patient care (Babiker et al., 2014). Here, we present the results of this study to evaluate the impact of educational intervention on secondary school students' knowledge, attitude and practical knowledge regarding to COVID-19 SIGNIFICANCE OF THE STUDY: In Egypt, changes every day of life have been rapid, with virus outbreaks, and an increasing death rate. Coronavirus is considered pandemic in Egypt as part of an ongoing worldwide coronavirus pandemic. The Ministry of Health and Population Egypt confirmed that the first case of COVID-19 in Egypt was on February 14, 2020 (Ministry of Health and Population Egypt, 2020). As the coronavirus pandemic rapidly spread across the world, there is a need to improve students' knowledge, attitude, and practical knowledge to help prevent and control disease among them. The emerging pandemic coronavirus (COVID-19) is considered a specific and unusual phenomenon. There are, however, no academic studies about the impact of educational intervention on secondary school students' knowledge, practices and attitudes regarding to COVID-19 in Egypt. Therefore, the current study represents the first impact of a structured teaching program regarding COVID -19 conducted in secondary school students in a city in Egypt within the first month of the COVID-19 outbreak. This study aims to evaluate the impact of educational intervention regarding COVID -19 on knowledge, attitudes, and practical knowledge among secondary school students in Egypt in the initial stage of the coronavirus pandemic (COVID-19) outbreak. Additionally, assessing students' knowledge is important in clarifying gaps and strengthening ongoing prevention efforts facilitating outbreak management of COVID-19 in Egypt and controlling the disease spread among students. AIM OF THE STUDY: The study aimed to evaluate the impact of educational intervention on secondary school students' knowledge, attitude and practical knowledge regarding to COVID-19. RESEARCH HYPOTHESIS: Secondary school students who will be exposed to educational intervention regarding COVID -19 will have improved in their knowledge, and the total knowledge score will be higher post-intervention compared to pre-intervention. Secondary school students' who will be exposed to educational intervention regarding COVID -19 will have improved in their attitude, and the total attitude score will be higher post-intervention compared to pre-intervention. Secondary school students' who will be exposed to educational intervention regarding COVID -19 will have improved in their practical knowledge, and the total practice score will be higher post-intervention compared to pre-intervention.

\section{Subjects And Methods}




\section{RESEARCH DESIGN:}

A pre/post-quasi-experimental research design was adopted in the current study.

\section{SETTINGS:}

The present study was conducted in Sohag city in Egypt.

\section{SUBJECTS:}

A convenience sample used to achieve the aim of the study. It includes 260 secondary school students in Sohag city through Google form spreadsheet, who meet the following inclusion criteria were as follows: secondary school students, aged 15 to 18 years, from both sexes (male and female) and welling to interact in the study.

\section{TOOL AND TECHIQUES OF DATA COLLECTION:}

After a comprehensive literature search and based on the most recent available information from the World Health Organization, the Center for Disease Control and Prevention (USA) and the Egypt Ministry of Health and a pre-validated questionnaire by (Zhong et al., 2020) was modified by the researchers as follows:

1-A self-administered questionnaire: - It was composed of four parts.

Part (1):- Demographic data included age, sex, school level, and residence.

Part (2): To assess knowledge regarding COVID -19, consisted of (30) items which include (definition of COVID -19, risk factors of COVID -19, sign \& symptoms of COVID -19, treatment, methods of transmission, 19 , and preventive measures of COVID - 19.

Part (3): To assess attitude regarding COVID -19, consisted of (6) items.

Part (4): To assess practical knowledge regarding COVID -19, consisted of 14) items.

Tool (2):- A health education Arabic booklet was prepared by the researchers including a structured teaching program regarding COVID -19.

\section{Scoring system:}

- The scoring system for the present study was designed as follows:

- Knowledge about COVID -19. It contains 30 questions; these questions were answered on a YES/NO basis option. A correct answer was assigned 1 point, and an incorrect answer was assigned zero points. The total knowledge score ranged from zero to 30 . 
- Knowledge about COVID -19. It contains 22 questions; these questions were answered on a true/false basis option. A correct answer was assigned 1 point, and an incorrect answer was assigned zero points. The total knowledge score ranged from zero to 22 , with high scores indicating better knowledge of COVID-19. Items were evaluated for internal reliability, using Cronbach's alpha coefficient was 0.72 (Fetters and Tilson, 2018)

\section{The total scores of students' knowledge were divided into three levels:-}

- Scores above ( $\geq 70 \%)$ considered good

- Scores between $50 \%-<70 \%$ were considered fair

- A score of less than $50 \%$ was considered poor.

- (B) Attitude toward COVID -19. It contains 6 questions; in the section on attitudes, scores were calculated based on the respondents' answers to each attitudinal statement, $1=$ strongly disagree, 2 $=$ disagree, $3=$ undecided, $4=$ agree, and $5=$ strongly agree. Scores were calculated by averaging respondents' answers to the six statements. Total scores ranged from six to 30 , with high scores indicating positive attitudes. The Likert scales were assessed for internal reliability, using Cronbach's a. Cronbach's alpha coefficient was 0.81 , indicating internal reliability.

\section{The total scores of student attitude were divided into three levels:-}

- A score above ( $\geq 70 \%$ ) considered good

- Scores between $50 \%-<70 \%$ were considered fair.

- A score of less than $50 \%$ was considered poor.

- (C) The scoring system for student practical knowledge was classified as a student's practice about COVID -19 with 14 items. In the section on practices, respondents were asked to respond "yes" or "no" to the items. A score of one was given to answers that reflected good practical knowledge, and a score of zero was given for answers that reflected bad practical knowledge. The total score ranged from zero to 14, with high scores indicating better practical knowledge.

\section{The total scores of adolescent student practical knowledge were divided into three levels:-}

- A score above ( $\geq 70 \%)$ considered good

- The scores between $(50 \%-<70 \%)$ considered fair

- A score of less than $50 \%$ was considered poor.

Validity and reliability:

Face and content validity of the tools for clarity, comprehensiveness, appropriateness, and relevance by a board of five experts' professors in pediatric nursing and community health nursing at Sohag university hospital with more than ten years of experience in the field were assessed; the board ascertained the face 
and content validity of the tools after modifications. Reliability was assessed through Cronbach's alpha reliability test $a=89 \%$. The tools' reliability was estimated by using the Pearson correlation coefficient test to compare variables. The Pearson correlation coefficient for the variables ranged between (P. $<0.5)$ and $(P .<0.001)$, which indicated a highly significant positive correlation between variables of the subjects.

\section{ETHICAL CONSIDERATION:}

Each secondary student was informed about the aim and benefits of the study in the first part before starting the questionnaire where every student could not be starting the questionnaire without consent to participate in data collection in the current study. Each student informed them that participation in the study was voluntary and that they had the right to withdraw from the study at any time before completing the questionnaire with no consequences, without giving any reason and that their responses would be held confidentially.

\section{DATA COLLECTION:}

The researchers used the online Google form spreadsheet to create the research. The researchers shared a link to the students to collect data that included an online questionnaire. The link was presented in Whats App groups. On the first page of the online questionnaire, students were informed about the background and objectives and expected outcomes of the KAP of the study. All the students' responses were gathered in an online spreadsheet to evaluate the impact of educational intervention program regarding COVID -19 on knowledge, attitudes, and practical knowledge among secondary school students. The online questionnaire was used three times. For the first time, it was used as a pre educational intervention application for the assessment of secondary school students' knowledge, attitude, and practices regarding COVID-19. Then, it was used another time as an immediate post educational intervention application and repeated follow up after one month to evaluate the effect of teaching program.

The average time spent for secondary school students completing the online questionnaire was approximately 6-8 minutes; sample was included in the study from 20 April to 2 May 2020. The online questionnaire was designed in English and translated into Arabic. The questionnaire was designed as a multiple-choice question (quiz). We provided the correct answers to all questions wrongly answered by the respondents as feedback. All questions and responses were based on the latest recommendations by the WHO. The content of the educational intervention included simple and clear information about COVID19. It also included the preparation of teaching materials i.e. photos, videos about ideal hand washing and PowerPoint presentation about COVID -19 and its preventive measures for protection, and health education the Arabic booklet was prepared by the researchers, including educational intervention regarding COVID -19 that was introduced to secondary school students in Whats App groups. The booklet was sent to students. This booklet contained all the information needed to know about COVID -19 as well as photos that clarified the information. The evaluation took place one month after the educational intervention, to examine the secondary school students' knowledge, attitude, and practical knowledge using a pre-posttest online questionnaire. 


\section{STATISTICAL ANALYSIS:}

The data obtained were reviewed, prepared for computer entry, coded, analyzed, and tabulated. Data entry and analysis were performed using the SPSS 17.0 statistical software package. Data are expressed as the mean, SD, number, and percentage. The Manwhitiny test was used to determine significance for numeric variables and using Person's correlation for a numeric variable in the same group, $P>0.05$ was not significant, $P<0.05$ was significant, $P<0.01$ was moderately significant and $P<0.001$ was highly significant.

\section{Results}

Out of 260 students who answered the questionnaires, (57.3\%) were female and (42.7\%) were male. The age of the participants ranged from 15 to 18 years old. (40\%) were 16 to 17 years of age. Regarding residence, nearly three - quarters $(74.00 \%)$ of students were from urban areas and $26 \%$ were from rural areas (Table 1).

Figure (1) shows an illustrated educational level among students and that most relevant of them (35.0\%) were on the third level.

Regarding students' sources of information about corvid-19, the results indicated that the main source of information about COVID-19 was social media (73\%), followed by television (49\%), which Facebook is the most frequently cited source of knowledge among social media, and followed by Whats App (Figure 2).

Table (2) shows the secondary school students' knowledge about COVID-19 pre/post and after one month of educational intervention implementation. This table indicates that there was an improvement in secondary school students' knowledge compared to pre educational intervention knowledge. There was a highly statistically significant difference between pre/post and after one month of educational intervention implementation to the secondary school student's knowledge regarding COVID-19 (P-value $<0.000)$. Out of all subjects, $260(100 \%)$ had poor pretest knowledge level. In the posttest $234(90.0 \%)$ secondary school students had a good knowledge level followed by $182(70.0 \%)$ who improved after educational intervention implementation. There was a highly statistically significant difference $(\mathrm{p}=$ $<0.000$ ) in the secondary school students' total knowledge mean scores as pre/immediate post and after one month of educational intervention implementation regarding COVID -19 (Table 2)

There was an improvement in secondary school students' attitudes compared to pre educational intervention knowledge. There was a highly statistically significant difference between pre/post and after one month of educational intervention implementation to the secondary school student's attitude regarding COVID-19 (P-value <0.000). Secondary school students' attitudes were measured with 6 items. The highest negative result was answered regarding the COVID-19-related attitude item: "feel anxious when you think of coronavirus disease / COVID-19". The highest positive result was answered regarding COVID-19-related attitude items: 'regular hand washing, maintaining social distancing and use of masks can protect'. However, the lowest positive attitude result answered is related to the attitude item: 'Egypt's 
strict measures can help win the battle against COVID-19 pre educational intervention implementation which improved after educational intervention implementation (Table 3). There was a highly statistically significant difference $(p=<0.000)$ in the secondary school students' attitude mean scores as pre/immediate post and after one month of educational intervention implementation regarding COVID -19 (Table 3). Out of all subjects, $202(77.7 \%)$ had a poor pretest attitude level followed by fair $(20.0 \%)$ and good $6(2.3 \%)$. In the posttest, all 260 secondary school students had a good attitude level which improved after educational intervention implementation (Table 3).

There was improvement among secondary school students' practical knowledge regarding COVID -19 pre/immediate post and after one-month educational intervention implementation, where there were highly significant differences $(P=0.000)$ with regard to practical knowledge of all the preventive measures from COVID -19 (Table 4). In the pretest educational intervention many preventive measures not practicing and secondary school students showed a low-performance rate, as out of $260(8.5 \%)$ participants were not practicing social distancing; $(8.5 \%)$ hand washing; $(0.0 \%)$ use disinfectants; $(22.8 \%)$ use of masks; $(40.0 \%)$ recently go to a crowded place; $(7.0 \%)$ stay at home and $(90.0 \%)$ shake hand upon the meeting of friends/family members/other, which improved after educational intervention implementation and secondary school students showed a high-performance rate. There was a highly statistically significant difference $(p=<0.000)$ in the secondary school students' practical knowledge mean scores as pre/immediate post and after one month of educational intervention implementation regarding COVID -19. Out of all subjects, 150 (57.7\%) had poor pretest practical knowledge levels, followed by fair (38.3\%) and good 10 (4.0\%). In the posttest, all secondary school students had good practical knowledge levels which improved after educational intervention implementation. It illustrated that secondary school students' mean scores for total practical knowledge regarding COVID -19 before and after the educational intervention implementation were improved, and there was a highly statistically significant difference $(p=<0.000)$ where the mean practice was 10.17 before the educational intervention compared to 12.84 after one month from educational intervention implementation (Table 4).

There was a highly statistically significant positive correlation between total knowledge scores, attitude, and practical knowledge at the post and after one-month educational intervention implementation $(P=0.004, P=0.005)$ (Table 5).

Table (1): Percentage distribution of secondary school students according to their characteristics $(\mathrm{N}=260)$ 


\begin{tabular}{|lll|}
\hline Characteristics of secondary school students & $\mathbf{N}=\mathbf{2 6 0}$ & $\%$ \\
\hline Gender & & \\
- Male $\quad$ Female & 149 & 57.3 \\
2-Age(years) & 111 & 42.7 \\
$\cdot 15 \otimes 16$ & & \\
$\cdot 16 \otimes 17$ & 78 & \\
$\cdot 17 \geq 18$ & 104 & 30.00 \\
& 78 & 40.00 \\
3-Residence: & & 30.00 \\
$\cdot \quad$ Urban. & & \\
$\cdot \quad$ Rural. & 192 & 74.00 \\
\hline
\end{tabular}

Table (2): Comparison of secondary school students' level of knowledge related to COVID-19 as pre/immediate post and after one-month educational intervention implementation $(\mathrm{N}=260)$

\begin{tabular}{|c|c|c|c|c|c|c|c|}
\hline \multirow[t]{2}{*}{ Items } & \multicolumn{2}{|c|}{$\begin{array}{l}\text { Pre educational } \\
\text { intervention }\end{array}$} & \multicolumn{2}{|c|}{$\begin{array}{l}\text { Immediate-post } \\
\text { educational intervention }\end{array}$} & \multicolumn{2}{|c|}{$\begin{array}{l}\text { After one month } \\
\text { educational intervention }\end{array}$} & \multirow{2}{*}{$\begin{array}{l}P \text { - } \\
\text { value }\end{array}$} \\
\hline & No. & $\%$ & No. & $\%$ & No. & $\%$ & \\
\hline $\begin{array}{l}\text { - Poor > } \\
\text { "50" }\end{array}$ & 260 & $100 \%$ & 0 & 0.0 & 0 & 0.0 & 0.000 \\
\hline $\begin{array}{l}\text {-Fair "50- } \\
\text { 70" }\end{array}$ & 0 & 0.0 & 200 & 61.4 & 182 & 70.0 & 0.000 \\
\hline $\begin{array}{l}\text {-Good" } \geq \\
\text { "70" }\end{array}$ & 0 & 0.0 & 210 & 80.6 & 234 & 90.0 & 0.000 \\
\hline $\begin{array}{l}\text { Total } \\
\text { knowledge }\end{array}$ & \multicolumn{2}{|c|}{$5.68 \pm 0.69$} & \multicolumn{2}{|c|}{$16.17 \pm 3.10$} & \multicolumn{2}{|c|}{$24.04 \pm 8.04$} & 0.000 \\
\hline
\end{tabular}

Table (3): Comparison of secondary school students 'level of attitude related to COVID-19 as pre/immediate post and after one month educational intervention $(\mathrm{N}=260)$ 


\begin{tabular}{|c|c|c|c|c|c|c|c|}
\hline \multirow{2}{*}{ Levels } & \multicolumn{2}{|c|}{$\begin{array}{l}\text { Pre-educational } \\
\text { intervention }\end{array}$} & \multicolumn{2}{|c|}{$\begin{array}{l}\text { Immediate-post } \\
\text { educational intervention }\end{array}$} & \multicolumn{2}{|c|}{$\begin{array}{l}\text { After one month } \\
\text { educational intervention }\end{array}$} & \multirow{2}{*}{$\begin{array}{l}\mathrm{P} \text { - } \\
\text { value }\end{array}$} \\
\hline & No & $\%$ & No & $\%$ & No & $\%$ & \\
\hline $\begin{array}{l}\text { - Poor > } \\
\text { "50" }\end{array}$ & 202 & (77.7\%) & 0 & 0.0 & 0 & 0.0 & 0.000 \\
\hline $\begin{array}{l}\text { - Fair "50: } \\
70 "\end{array}$ & 52 & $(20.0 \%)$ & 0 & 0.0 & 0 & 0.0 & 0.000 \\
\hline $\begin{array}{l}\text { - Good" } \geq \\
\text { "70" }\end{array}$ & 6 & $(2.3 \%)$ & 260 & $(100 \%)$ & 260 & $(100 \%)$ & 0.000 \\
\hline $\begin{array}{l}\text { Total } \\
\text { attitude }\end{array}$ & \multicolumn{2}{|c|}{$1.17 \pm 1.60$} & \multicolumn{2}{|c|}{$4.06 \pm 1.73$} & \multicolumn{2}{|c|}{$5.84 \pm 1.12$} & 0.000 \\
\hline
\end{tabular}

Table (4): Comparison of secondary school students' levels of practical knowledge related to COVID-19 as pre/immediate post and after one month educational intervention $(\mathrm{N}=\mathbf{2 6 0})$

\begin{tabular}{|c|c|c|c|c|c|c|c|}
\hline \multirow[t]{2}{*}{ Levels } & \multicolumn{2}{|c|}{$\begin{array}{l}\text { Pre-educational } \\
\text { intervention }\end{array}$} & \multicolumn{2}{|c|}{$\begin{array}{l}\text { Immediate-post } \\
\text { educational intervention }\end{array}$} & \multicolumn{2}{|c|}{$\begin{array}{l}\text { After one month } \\
\text { educational intervention }\end{array}$} & \multirow{2}{*}{$\begin{array}{l}\mathrm{P}- \\
\text { value }\end{array}$} \\
\hline & No & $\%$ & No & $\%$ & No & $\%$ & \\
\hline - Poor > "50 " & 150 & $(57.7 \%)$ & 0 & 0.0 & 0 & 0.0 & 0.000 \\
\hline -Fair "50: 70" & 100 & $(38.3 \%)$ & 0 & 0.0 & 0 & 0.0 & 0.000 \\
\hline -Good" $\geq$ "70" & 10 & $(4.0 \%)$ & 260 & $(100 \%)$ & 260 & $(100 \%)$ & 0.000 \\
\hline $\begin{array}{l}\text { Total practical } \\
\text { knowledge }\end{array}$ & \multicolumn{2}{|c|}{$10.17 \pm 1.60$} & \multicolumn{2}{|c|}{$19.06 \pm 1.73$} & \multicolumn{2}{|c|}{$24.84 \pm 2.12$} & 0.000 \\
\hline
\end{tabular}

Table ( 5 ): Correlation coefficient between total secondary school students' knowledge, attitude and practical knowledge scores regarding COVID -19 during pre/immediate post and after one month of educational intervention implementation $(\mathrm{N}=260)$ 


\begin{tabular}{|c|c|c|c|c|c|c|}
\hline \multirow{3}{*}{ Items } & \multicolumn{6}{|c|}{ Practice } \\
\hline & \multicolumn{2}{|c|}{ Pre-program } & \multicolumn{2}{|c|}{ Immediate-post } & \multicolumn{2}{|c|}{ After one month } \\
\hline & $\mathbf{R}$ & $\mathbf{P}$ & $\mathbf{R}$ & $\mathbf{P}$ & $\mathbf{R}$ & $\mathbf{P}$ \\
\hline $\begin{array}{l}\text { - Total knowledge posteducational } \\
\text { intervention }\end{array}$ & 0.035 & 0.814 & -- & - & -- & -- \\
\hline $\begin{array}{l}\text { - Total attitude post- educational } \\
\text { intervention }\end{array}$ & -- & -- & 0.243 & $0.004^{\star * *}$ & 0.412 & $0.005^{\star \star \star}$ \\
\hline
\end{tabular}

\section{Discussion}

The world is now facing a Coronavirus pandemic which is considered highly infectious. Several preventive measures have been mentioned to prevent its spread among students. However, for these preventive measures to be effective, the students require appropriate and sufficient knowledge. Knowledge, attitude, and practices are crucial to prevent and control the disease. Health care teams include nurses and are responsible for providing knowledge, delivering good quality management, and protecting individuals from an illness during the epidemic prevalence period (Askarian et al., 2013). Here, we present the results of this study to evaluate the impact of educational intervention on secondary school students' knowledge, practices and attitudes regarding to COVID-19.

The present study revealed that more than half of the participants were female and less than half were male. The age of the participants ranged from 15 to 18 years old. These results were nearly supported by the study conducted by (Dafni and Maddalena, 2020) who found in his study in Italy that the age of participants ranged from 14 to 19 years old and that females were more than half of the participants

The present study indicated that the main source of information about COVID-19 was social media. These results followed the results of (Hamaza et al., 2020) in her cross-sectional study on awareness and knowledge of COVID-19 among senior pharmacy students.

These results are also strongly supported and similar to findings in which the main source of Middle East respiratory syndrome (MERS) information was reported to be the internet and social media (Khan et al., 2014). This indicates that secondary school students are conducting on the internet, social media, and online information as is becoming one of the principal and rapid ways to obtain information, compared with other resources. The Egyptian Ministry of Health and Population and the World Health Organization (WHO) have provided information about COVID-19 through their websites and they are recommending people to be aware of updates relating to knowledge about COVID-19 (World Health Organization, 2020 and Hoda, 2016). Similarly, a previous study mentioned that the internet was the main source of information about COVID- 19 (Feng et al., 2020). This reflects the importance of the Internet in promoting health, especially during infectious diseases and pandemics. Technology presence in these lock-down months plays an important role in providing knowledge and helps students continue their learning. More 
attention should be given to utilizing technology particularly social media resources, especially Facebook or Whats App, as they help promote public health education among students.

The current study indicates that there was an improvement in secondary school students' knowledge compared to pre educational intervention knowledge. There was a highly statistically significant difference between pre/post and after one month of educational intervention implementation to the secondary school student's knowledge regarding COVID-19 ( $P$-value $<0.000)$. This may be related to the effect of teaching programs regarding COVID-19 on the knowledge, of students and the booklet, which covered all identified needs and knowledge gaps about the topic among secondary school students. Students need to have sufficient and correct knowledge about COVID-19 from a biological and scientific point of view and not only socially as correct information during the pandemic is considered the key point on which attention in this research to focus.

The present study revealed that out of all subjects had poor pretest knowledge levels; in the posttest, most of the secondary school students had good knowledge levels, which indicated the importance of educational intervention that were effective in improving the students' knowledge. This reflected the desire of the students to increase and improve their awareness and know the value of health and the importance of good practicing during COVID - 19 as a method for prevention and protection against infection with coronavirus.

The current study indicated that there was an improvement in secondary school students' attitudes compared to pre educational intervention knowledge. There was a highly statistically significant difference between pre/post and after one month of educational intervention implementation to the secondary school student's attitude regarding COVID-19 (P-value <0.000). This is related to the correlation between the students' attitude and knowledge which indicates that sufficient knowledge reflects their positive attitude among students towards COVID-19.

The current study revealed that secondary school students' attitudes were measured with 6 items. The highest negative result was answered regarding the COVID-19-related attitude item: "feel anxious when you think of coronavirus disease / COVID-19". This was a country such as Egypt, where stress and anxiety may occur because basic prevention measures are unavailable (World Health Organization, 2020), and there is insufficient information about the disease. The knowledge that is a prerequisite for achieving positive attitudes and promoting positive behaviors among students is necessary, which helps individuals' cognition to invest a sense towards the infection regarding COVID-19.

The current study revealed that there was improvement among secondary school students' practical knowledge regarding COVID -19 pre/immediate post and after one-month educational intervention implementation, where there were highly significant differences $(P=0.000)$ with regard to practice of all the preventive measures from COVID -19. This is related to the correlation between the secondary school students' attitude and practical knowledge, which indicates that their positive attitude is affecting their action towards COVID-19. 
The current study revealed that in the pretest educational intervention, many preventive measures not practicing and secondary school students showed a low-performance rate, as out of $260(22.8 \%)$ of participants were not practicing the use of masks. These results follow the results of (The Novel

Coronavirus Pneumonia Emergency Response Epidemiology Team, 2020) who reported in her study that the students showed poor practice when using masks as a protective measure. This was related to the lower level of knowledge about the importance of wearing masks. This is also supported by the findings from a previous study by (World Health Organization, 2020), which mentioned that only approximately one-third of the participants were wearing face masks.

The current study reflected that, out of all subjects, more than half of them had poor pretest practice levels and in the posttest, all secondary school students had good practical knowledge levels that improved after educational intervention implementation. It illustrated that secondary school students' mean scores for total practical knowledge regarding COVID -19 before and after the educational intervention implementation were improved, and there was a highly statistically significant difference ( $p=$ $<0.000$ ) where the mean practice was 10.17 before the educational intervention compared to 12.84 after one month from educational intervention implementation. This finding supported the third stated research hypnosis which stated that secondary school students' who will be exposed to structured teaching programs regarding COVID -19 will have improved in their practice, and the total practice score will be higher post-intervention than pre-intervention.

The present study revealed that there was a highly statistically significant positive correlation between total knowledge scores, attitude and their practice at the post and after one-month educational intervention implementation. This can be explained by the fact that research hypnosis was achieved and concluded the success of the educational intervention and it had an impact on secondary school students' knowledge, attitude and practice regarding COVID -19 and values the need for a well-organized educational intervention to promote the knowledge, attitude and practice of secondary school students and emphasized the readiness of students to gain more information.

\section{Conclusion}

In light of the study findings, it was concluded that secondary school students' knowledge, attitude, and practice improved after exposure to the educational intervention. The provision of educational intervention was significantly effective in increasing knowledge level, attitude, and practice among secondary school students regarding COVID-19. Therefore, the stated research hypnosis was statically supported. Secondary school students have poor knowledge regarding COVID-19. It is reflected in their negative attitude and poor healthy preventive practices towards COVID-19 that have improved after the educational intervention. This will help protect them from COVID-19.

\section{RECOMMENDATIONS:}

Based on the findings of the current study, the following recommendations are proposed: 
1. Training programs for teachers to be well prepared to provide instructions about prevention and control about COVID-19 for students.

2. Training programs for nurses to be well prepared to provide secondary school students with appropriate knowledge and practices about COVID-19 through verbal and written instructions.

3. It is important to encourage cooperation between educational institutions, medical care providers, and health personnel to educate secondary school students about COVID-19 that will help in increasing awareness, decreasing the spread of disease, prevention, and control.

\section{Declarations}

\section{COMPLIANCE WITH ETHICAL STANDARDS}

\section{ETHICS APPROVAL}

Each secondary student was informed about the aim and benefits of the study in the first part before starting the questionnaire where every student could not be starting the questionnaire without consent to participate in data collection in the current study. Each student informed them that participation in the study was voluntary and that they had the right to withdraw from the study at any time before completing the questionnaire with no consequences, without giving any reason and that their responses would be held confidentially.

\section{CONSENT FOR PUBLICATION}

Not applicable.

\section{CONFLICTS OF INTEREST}

The authors declare no potential conflicts of interest concerning the research, authorship, and/or publication of this article.

\section{FUNDING:}

No funding sources

\section{ACKNOWLEDGMENT:}

The authors thank all the participants involved in this study for their cooperation and support and for spending their valuable time filling the online questionnaire on the COVID-19 pandemic.

\section{References}


1. Abdelhaz, A.S., Z. Mohammed, M.E. Ibrahim, et al. (2020). Knowledge, Perceptions, and Attitude of Egyptians towards the Novel Coronavirus Disease (COVID-19). J Community Health, DOI: 10.1007/s10900-020-00827-7.

2. Askarian, M., M. Danaei, and V. Vakili, A. (2013). Knowledge, Attitudes, and Practices Regarding Pandemic H1N1 Inuenza Among Medical and Dental Residents and Fellowships in Shiraz, Iran. Int J Prev Med. 4(4): p. 396-403.

3. Babiker, A., M. El Husseini, A. Al Nemri, et al., (2014). Healthcare professional development: Working as a team to improve patient care. Sudanese journal of pediatrics. 14(2): p. 9-16.

4. Banerjee, M., Chakraborty, S., Pal, R. (2020). Diabetes self-management amid COVID-19 pandemic, Diabetes Metab Syndr Clin Res Rev [Internet], [cited 2020 Apr 15]; Available from: [Google Scholar]

5. Carsetti, R., M.M. Rosado, S. Donnanno, et al. (2005). The loss of memory B cells correlate with clinical disease in common variable immunodeficiency. J Allergy Clin Immunol. 115(2): p. 412-7 DOI:10.1016/j.jaci.2004.10.048.

6. Chirwa, G.C. (2019). Socioeconomic Inequality in Comprehensive Knowledge about HIV in Malawi, Malawi Med J, 31:104-11, 10.4314/mmj.v31i2.1 [PMC free article] [PubMed] [CrossRef] [Google Scholar]

7. Chirwa, G.C. (2020). Who knows more, and why? Explaining socioeconomic-related inequality in knowledge about HIV in Malawi, Sci African, 7:e00213 10.1016/j.sciaf.2019.e00213 [CrossRef] [Google Scholar]

8. Dafni, S., Maddalena, D. (2020). Knowledge, attitude and practice of secondary school students toward COVID-19 epidemic in Italy: a cross selectional study.

9. Fan, Y., Zhang, S., Li, Y., Li, Y., Zhang, T., Liu, W. (2020). Development and psychometric testing of the Knowledge, Attitudes, and Practices (KAP) questionnaire among student Tuberculosis (TB) Patients (STBP-KAPQ) in China. BMC Infect Dis [Internet]. 2018 [cited 2020 May 12]; 18(1). Available from: [Google Scholar]

10. Feng, S., C. Shen., N. Xia, W. Song, M. Fan, and B.J. (2020). Cowling, rational use of face masks in the COVID19 pandemic. Lancet Respire Med, 8(5): p. 434-436 DOI: 10.1016/s2213-2600(20)30134-x.

11. Fetters L, Tilson J. (2018): Evidence Based Physical Therapy. Philadelphia, PA: FA Davis.

12. Hamaza, M. S., Osama, A. B. Mohamed, M. El. (2020). Cross-sectional study on awareness and knowledge of COVID-19 among senior pharmacy students.

13. Hoda J. (2016): Identification of information types and sources by the public for promoting awareness of Middle East respiratory syndrome coronavirus in Saudi Arabia. Health Education Research; 31(1):12-23. Doi: 10.1093/her/cyv061. [PMC free article] [PubMed] [CrossRef] [Google Scholar]

14. Jordan, C. (2020). "Coronavirus outbreak shining an even brighter light on internet disparities in rural America", TheHill, Retrieved 2020-03-23. 
15. Khalil, A., Abdalrahim, M. (2014). Knowledge, attitudes, and practices towards prevention and early detection of chronic kidney disease: Knowledge regarding CKD. Int Nurs Rev.; 61:237245. [PubMed] [Google Scholar]

16. Khan, M.U., S. Shah, A. Ahmad, and O. Fatokun. (2014). Knowledge and attitude of healthcare workers about Middle East Respiratory Syndrome in multispecialty hospitals of Qassim, Saudi Arabia, BMC Public Health, 14: p. 1281 DOI: 10.1186/1471-2458-14-1281.

17. Matsumoto, T. E.L.A., Tongol-Rivera, P., Villacorte, E.A., Angluben, R.U., Jimba, M., Kano, S. (2015). Patient Knowledge on Malaria Symptoms Is a Key to Promoting Universal Access of Patients to Effective Malaria Treatment in Palawan, the Philippines. Muela Ribera J, editor. PLOS ONE; 10:e0127858. [Google Scholar]

18. Ministry of Health and Population Egypt. "MOHP" (2020). COVID-19 in Egypt, available at https://www.care.gov.eg/EgyptCare/index.aspx

19. Ministry of Health-Egypt. (2020). COVID-19 Overview. May16; Available from: https://www.care.gov.eg/EgyptCare/Index.aspx.

20. National Health Commission of the People's Republic of China. (2020). A protocol for community prevention and control of the 2019 novel coronavirus (2019-nCoV) infected pneumonia (trial version). http://www.nhc.gov.cn/jkj/s3577/202001/dd1e502534004a8d88b6a10f329a3369.shtml (access Feb 16, 2020).

21. Pal, R., Bhadada, S. (2020). Should anti-diabetic medications be reconsidered amid COVID-19 pandemic? Diabetes Res Clin Pract; 108146 [Google Scholar]

22. Pal, R., Bhansali, A. (2020). COVID-19, Diabetes Mellitus, and ACE2: The conundrum. Diabetes Res Clin Pract; 108132 [Google Scholar]

23. Podder, D., Paul, B., Dasgupta, A., Bandyopadhyay, L., Pal, A., Roy, S. (2019). Community perception and risk reduction practices toward malaria and dengue: a mixed-method study in slums of Chetla, Kolkata. Ind J Public Health, 63:178. 10.4103/ijph.IJPH_321_19 [PubMed] [CrossRef] [Google Scholar]

24. Rana, M., Sayem, A., Karim, R., Islam, N., Islam, R., Zaman, T.K. (2020). Assessment of knowledge regarding tuberculosis among non-medical university students in Bangladesh: a cross-sectional study. BMC Public Health [Internet], 2015 Dec [cited 2020 May 12]; 15(1). Available from: [Google Scholar]

25. Ricardo, T., Bergero, L.C., Bulgarella, E.P., Previtali, M.A. (2018). Knowledge, attitudes and practices (KAP) regarding leptospirosis among residents of riverside settlements of Santa Fe, Argentina. Recuenco S, editor. PLoS Negl Trop Dis; 12:e0006470. [Google Scholar]

26. Shereen, M., Khan, S., Kazmi, A., Bashir, N., Siddique, R. (2020). COVID-19 infection: origin, transmission, and characteristics of human coronaviruses. J Adv Res. 24:91-8. 10.1016/j.jare.03.005 [PMC free article] [PubMed] [CrossRef] [Google Scholar]

27. Taber, K. (2018). The Use of Cronbach's Alpha When Developing and Reporting Research Instruments in Science Education, Research in Science Education; 48:1273-96. [Google Scholar]. 
28. Tang, D., Tou, J., Wang. J., Chen. Q., Wang, W., Huang, J., et al. (2020). Prevention and control strategies for an emergency, limited-term, and elective operations in pediatric surgery during the epidemic period of COVID-19. World J Pediatr Surg. 3:e000122 10.1136/wjps-2020-000122 [CrossRef] [Google Scholar]

29. The Novel Coronavirus Pneumonia Emergency Response Epidemiology Team. (2020).The epidemiological characteristics of an outbreak of 2019 novel coronavirus diseases (COVID-19) in China, Chin J Epidemiol; 41:145-51. [PubMed] [Google Scholar]

30. WHO Coronaviruses (COVID-19) (2020). Available online at https://www.who.int/news-room/q-adetail/q-a-coronaviruses.

31. World Health Organization. (2020). Coronavirus Disease 2019(COVID-19) Situation Report117.situationreports/20200311-sitrep-51-COVID-19.pdf?sfvrsn=1ba62e57_102020 May 16, 2020]; Available https://www.who.int/emergencies/diseases/novel-coronavirus-2019 31- Ministry of HealthEgypt. COVID-19 Overview, May16 2020]; Available from: https://www.care.gov.eg/EgyptCare/Index.aspx.

32. World Health Organization. (2020). declares novel coronavirus (2019-nCoV) sixth public health emergency of international concern. Euro surveillance: bulletin Europeen sur les maladies transmissibles = European communicable disease bulletin; 25(5). Epub 2020/02/06.

33. World Health Organization. (2020). WHO announces the COVID-19 outbreak a pandemic. http://www.euro.who.int/en/health-topics/health-emergencies/coronavirus covid19/news/news/2020/3/who-announces-COVID-19-outbreak-a-pandemic [Accessed 12 March 2020].

34. Zhong B-L, Luo W, Li H-M, et al. (2020): Knowledge, attitudes, and practices towards COVID-19 among Chinese residents during the rapid rise period of the COVID-19 outbreak: A quick online crosssectional survey, International Journal of Biological Sciences; 16(10):1745-1752. doi:

10.7150/ijbs.45221. [PMC free article] [PubMed] [CrossRef] [Google Scholar]

\section{Figures}




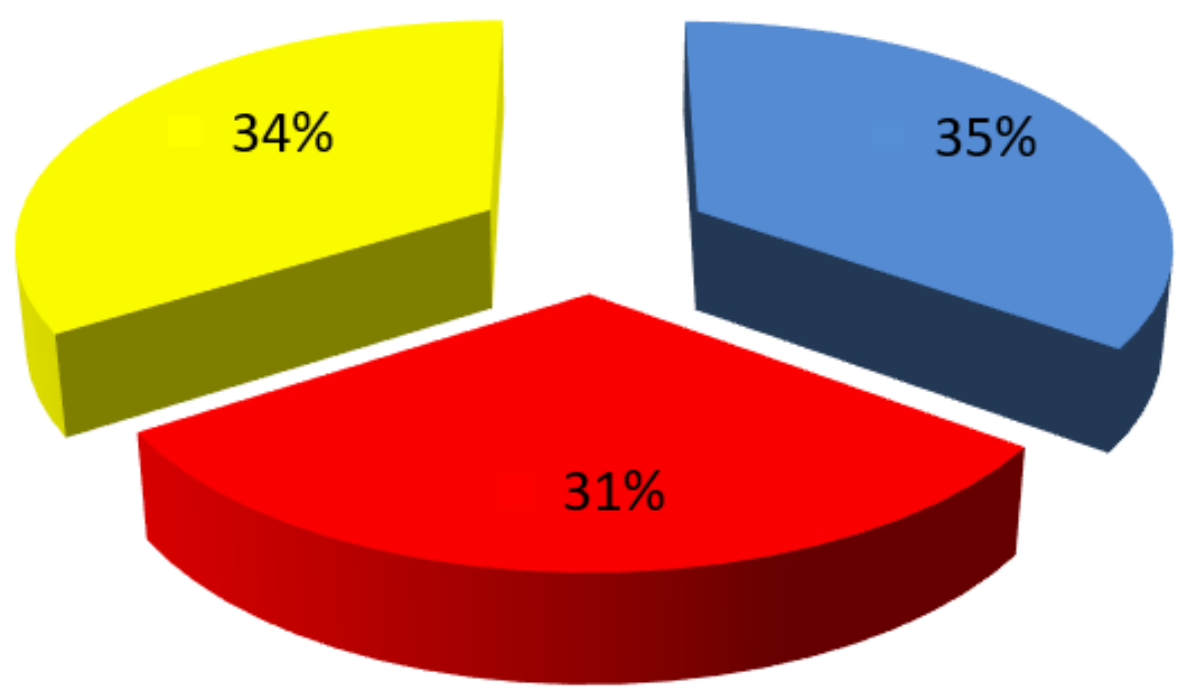

Third

Second

First

Figure 1

Percentage distribution of secondary school students according to their educational level $(\mathrm{N}=260)$.

\section{Chart Title}

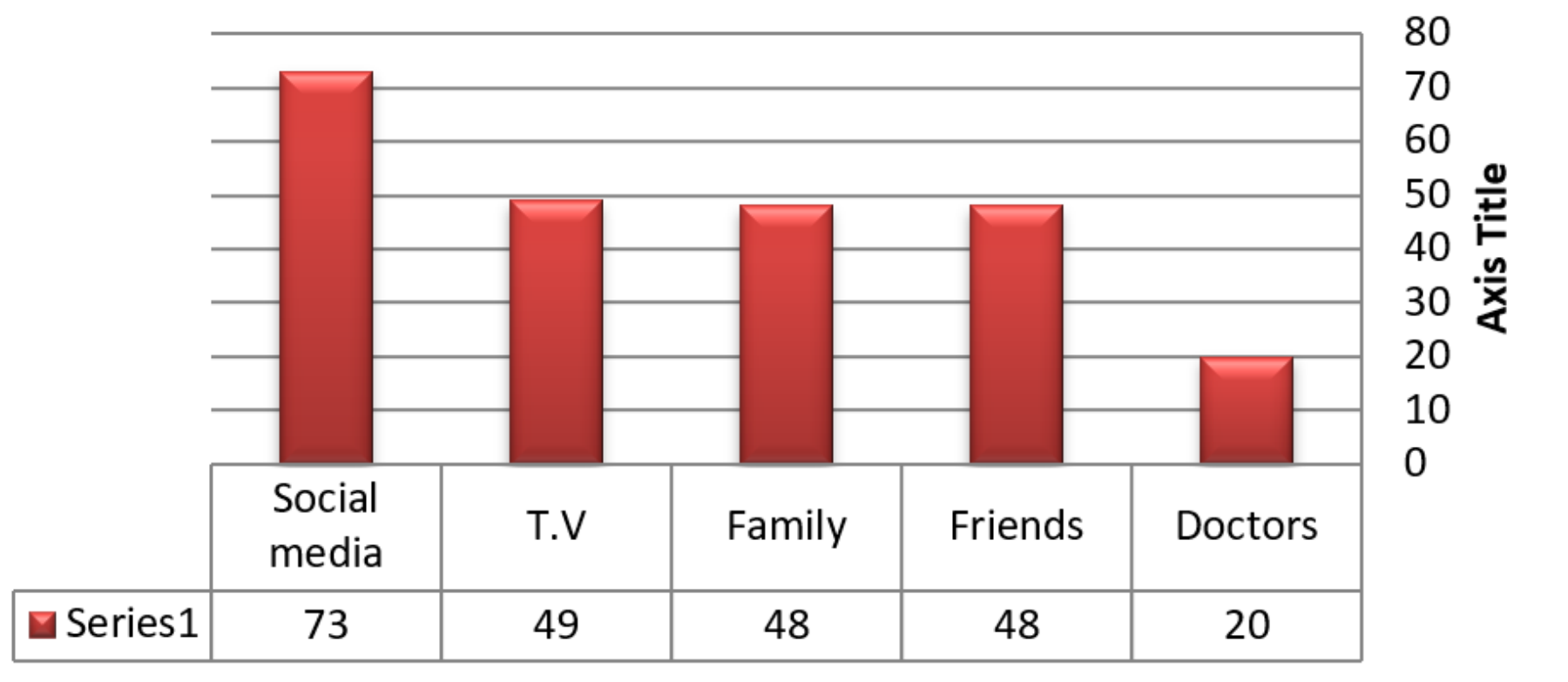

Figure 2 
Percentage distribution of secondary school students according to their source of information about COVID-19 $(\mathrm{N}=260)$. 